\title{
CONSIDERAȚII ASUPRA DECORULUI STATUETELOR ANTROPOMORFE GUMELNIȚENE
}

Radian-Romus Andreescu

\section{CONSIDERATIONS ABOUT THE DECORATION OF ANTROPOMORPHIC FIGURINES FROM GUMELNIȚA CULTURE}

\begin{abstract}
The article gives an analysis of the decoration found on the anthropomorphic clay statuettes belonging to Gumelnita culture. The main decoration technique was the incision. Without doubt there were some patterns according to which statuettes were decorated. The analysis proved the existence of two main decoration types placed on the statuettes torso. The first has as main elements "face to face" bands (fig. 1, 2). The second is composed of geometrical elements, triangles and rhombs, framed by oblique incisions. Other decoration motifs are incised bands placed on the statuettes neck and "face to face" bands on the legs. Their fragmentary state makes difficult a real and entire reconstruction of the decoration on the statuettes belonging to Gumelnita culture. The incised decoration was interpreted as clothes or tattoos. The analysis of the statuettes distribution showed that they are more numerous in Western Walachia. The decoration can be interpreted as a way of identification for the communities, considering that the second type of decoration is more often found in Western Walachia. Following the same idea the decoration can identify certain persons among a community. Further researches in a region with more Gumelnita sites could bring precious information by comparative analysis of decoration motifs on the statuettes belonging to Gumelnita culture.
\end{abstract}

Keywords: decoration, decoration motifs, identity, community

Cuvinte cheie: decor, motive decorative, identitate, comunitate

Articolul de faţă îşi propune o analiză mai detaliată a decorului statuetelor din lut aparținând civilizației gumelnițene. Un prim demers în acest sens a fost făcut în lucrarea noastră despre plastica antropomorfă gumelnițeană (Andreescu 2002). Descoperirile din ultimi ani, chiar dacă nu sunt foarte numeroase, vin să completeze anumite aspecte legate de decorarea statuetelor. Articolul se bazează pe analiza directă a pieselor, în special al acelora provenind din două mari loturi descoperite la Căscioarele şi Vităneşti. Analiza a avut în vedere statuetele modelate în picioare sau aşezate, care au corpul decorat cu incizii.

Una din dificultățile majore întâmpinate în cazul acestei analize l-a reprezentat starea de fragmentare a statuetelor. Practic nu a fost descoperită o statuetă care să nu aibă o parte, mai mare sau mai mică, lipsă. Statuetele decorate, relativ întregi, sunt foarte puține, iar decorul de pe ele, ca şi cel de pe fragmente, este de multe ori deteriorat. În aceste condiții încercările de reconstituire a motivelor decorative au o anumită doză de relativitate. Tehnica de decorare folosită este incizarea, fiind descoperite peste 200 de piese decorate în această tehnică. Modul de executare a inciziilor este variat, de la linii neglijent trasate la motive îngrijit incizate, sau de la incizii superficiale la crestături adânci. În unele cazuri inciziile au fost încrustate cu pastă albă sau roşie.

Analiza motivelor decorative de pe statuetele gumelnițene, arată existența indubitabilă a două tipuri principale de decor (Andreescu 2002).

Primul tip (I) are ca elemente principale benzi afrontate trasate pe pieptul statuetelor, de regulă dreptunghiulare, uneori cu linii incizate la interior (Fig 1, 2; P1.1; 6/1-3). De obicei aceste benzi acoperă sânii dar sunt şi cazuri când sunt 
plasate sub ei. Aceste elemente ar sugera o piesă vestimentară, un fel de vestă descheiată. Modurile de realizare sunt diferite, de la reprezentări realiste în care sunt figurate şi cutele pe care acest posibil veşmânt le face pe sânii personajului, până la sugerarea lui prin câteva linii verticale sau orizontale neglijent trasate. Decorul se continuă pe spatele statuetei prin câteva linii trasate prin părțile laterale. Pe spatele statuetelor se delimitează clar două variante de decor. Într-o primă variantă, IA, întâlnim aceleaşi benzi afrontate aflate pe față (Fig. 1, Pl. 1/1-5; 6/1,2).

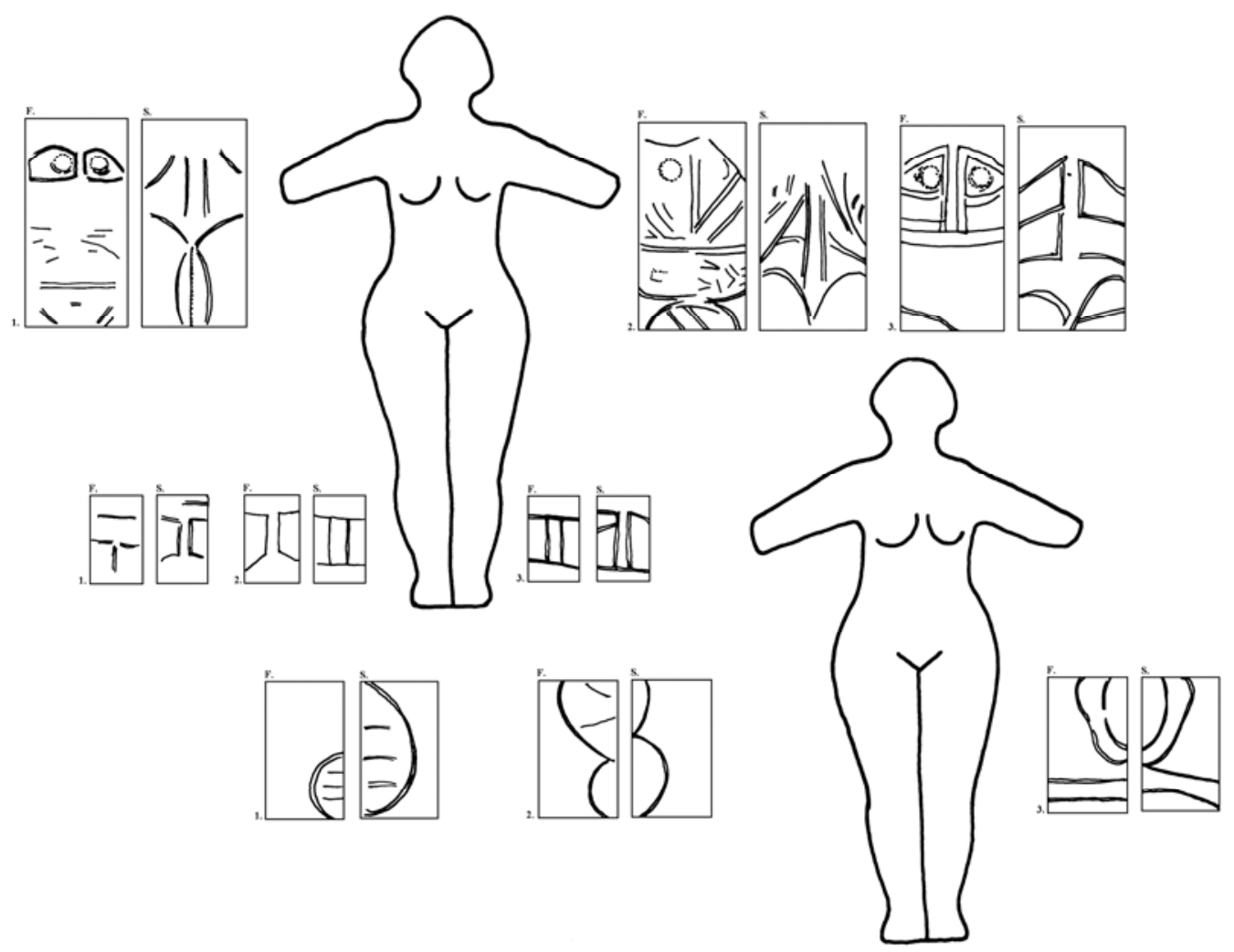

Fig 1. Decor tip IA

A doua variantă, IB, cuprinde statuetele care au pe spate, la partea superioară, o bandă orizontală în care se găsesc linii orizontale, cercuri sau mici incizii (Fig. 2; P1.1/6-12; 6/3)

Există se pare şi o a treia variantă în care cele două elemente, benzile afrontate şi cele orizontale se combină, variantă atestată prin două fragmente de statuete (Pl. 4/4,5).

Un mod neobişnuit de reprezentare a acestui tip de decor este întâlnit pe o statuetă descoperită la Popeşti, în acest caz benzile afrontate au fost realizate prin împunsături (Pl. 4/3)

Interpretarea acestui tip de decor este relativ dificilă având în vedere şi documentaţia incompletă. Totuşi, benzile afrontate de pe față sugerează mai degrabă un veşmânt decât un desen simbolic. Banda orizontală cu care se continuă acest decor pe spate ar sugera un fel de vestă. Mai curioasă este continuarea acestui decor pe spate în cazul benzilor afrontate. În acest caz am avea două piese vestimentare care ar îmbrăca părțile laterale ale corpului. Ele ar fi putut fi prinse pe fața şi pe spate prin accesorii, cum ar fi şireturile, dar acestea nu apar figurate pe nici o statuetă.

Lipsesc totuşi, în majoritatea cazurilor, elementele de decor de pe umerii statuetelor care să sugereze un vesmânt. Mai mult, o statuetă de la Gărăgău care are în faţă benzi afrontate, are pe spate o bandă care se continuă pe fața brațelor întinse lateral cu câte o fâşie îngustă, lăsând impresia că aceasta este cumva agăţată de umeri (Pl. 1/9). 


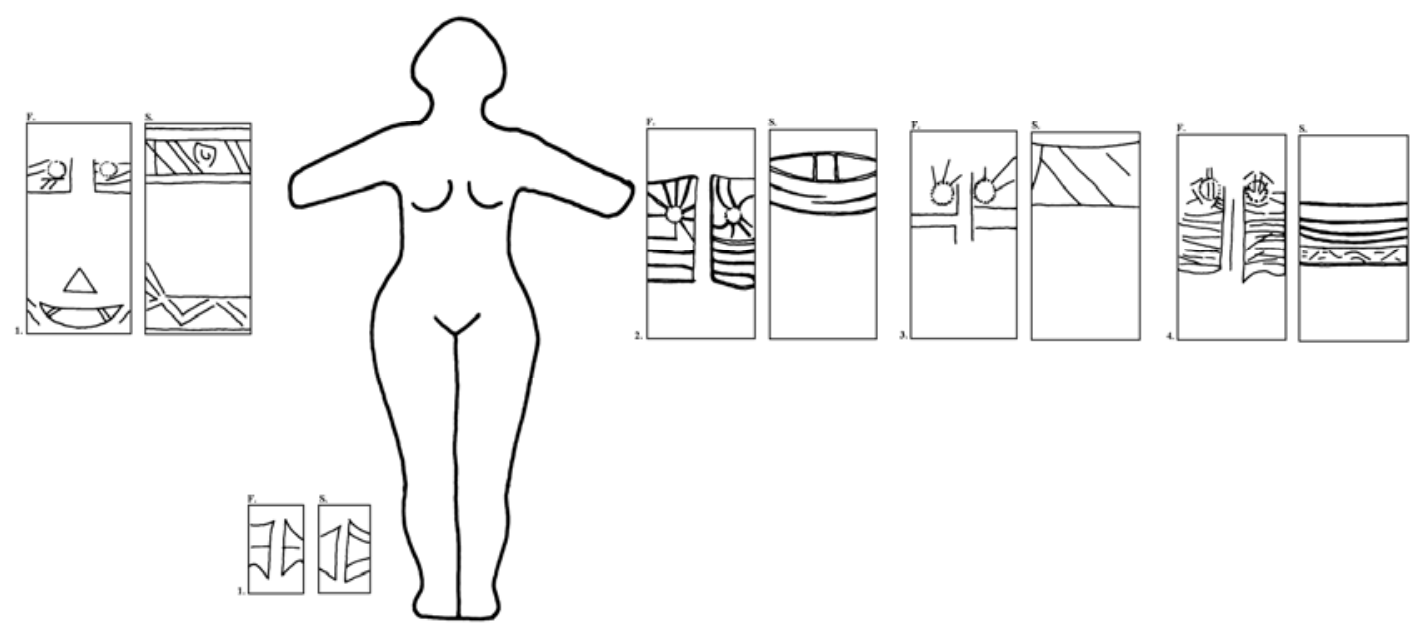

Fig. 2. Decor tip $I B$

Al doilea tip de decor, II, este ceva mai complex şi este mai bine ilustrat în special prin descoperirile din vestul Munteniei (Fig. 3; Pl. 2; $5 / 1 ; 6 / 4-6 ; 7 / 3)$

În faţă, pe pieptul statuetelor, se află o linie orizontală, iar între sâni două linii paralele sau oblice, terminate în unghi, ca un fel de pentagon, uneori cu incizii sau o spirală la interior. Sub el sunt incizate un romb sau un triunghi încadrate de linii oblice cere se continuă prin părțile laterale până pe spatele statuetei.

Pe spate, la baza capului, se află de obicei un triunghi, iar sub el o succesiune de romburi şi triunghiuri încadrate de linii oblice care se unesc în părțile laterale cu cele de pe față. În unele cazuri aceste elemente lipsesc fiind incizate doar liniile oblice.

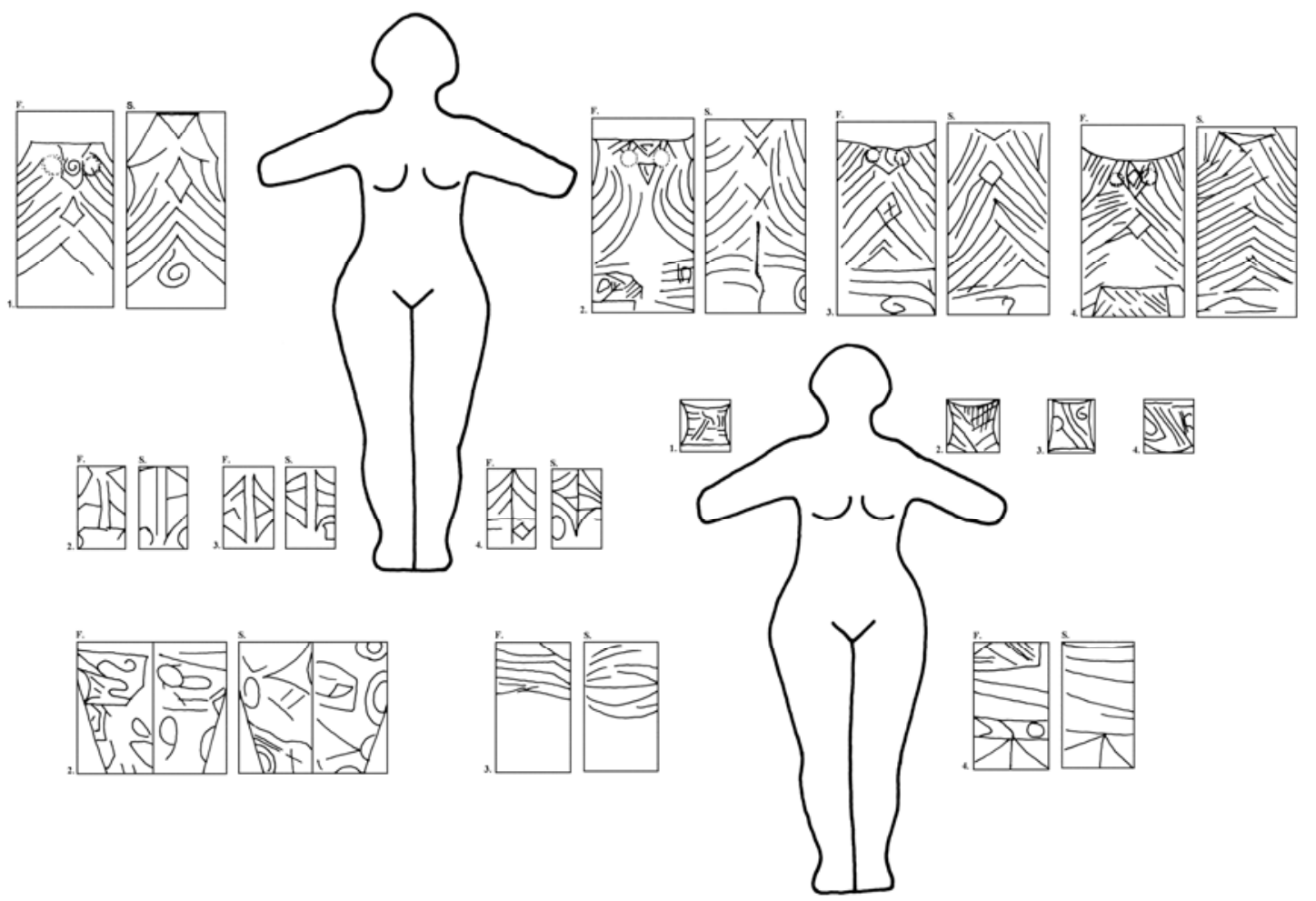

Fig 3. Decor tip II 
În ceea ce privește semnificația acestui decor, liniile oblice de pe fața, linii care se unesc prin părțile laterale cu cele de pe spate, ar putea sugera cutele unui veşmânt. Prezența elementelor geometrice pe față și pe spate ar reprezenta în acest caz anumite simboluri aflate pe aceste veşminte.

O variantă interesantă a acestui tip de decor este ilustrată de două piese descoperite la Vităneşti şi Ciolăneşti (Pl. 4/1,2). Decorul (ca şi morfologia) este aproape identic cu cel de pe statuetele cucuteniene (Monah 1997), dar cu elemente comune cum ar fi pentagonul de pe piept şi liniile oblice de pe trunchi* ${ }^{*}$.

Aceste două tipuri de decor sunt cele care sunt cel mai frecvent întâlnite, desigur cu o mare variaţie în ceea ce priveşte executarea lor.

Alături de aceste motive principale plasate pe trunchiul statuetelor, se întâlnesc şi altele, cu o frecvență mult mai redusă însă.

Unele statuete au la gât o bandă incizată (prelungită uneori şi la partea superioară a trunchiului) care are la interior diverse linii, cercuri sau spirale (Pl. 3/1-3, 5,6; 5/1; 6/3-5; 7/1-3).

Motivele decorative sunt mai rare pe fese şi pe picioare şi constau de obicei în incizii orizontale, cercuri, spirale, linii în unghi (Pl. $3 / 9,12 ; 5 / 1,2)$. Nu poate fi făcută o analiză a acestui decor dat fiind faptul că sunt puține piese. Este asociat de obicei cu tipul de decor II şi pare a fi mai des întâlnit în fazele mai vechi ale culturii. De altfel cercurile şi spiralele sunt întâlnite şi pe statuetele, puține de altfel, ale culturii Boian (Comşa 1974).

Un element de decor specific şi frecvent utilizat este acela al benzilor afrontate aflate pe gambele statuetelor ( $\mathrm{Pl}$. 3/4,7,8; 5/1,2; 6/1,2; 7/1-3). Benzile sunt fie dreptunghiulare fie, mai ales, lățite la capete, uneori având la interior incizii oblice sau orizontale. Acest elemente sunt asociate cu ambele tipuri de decor descrise mai sus. Interpretarea acestora ca accesorii vestimentare este plauzibilă deşi şi aici (ca şi în cazul benzilor de pe trunchi) ele ar îmbrăca părțile laterale ale gambelor. Modul de prindere

\footnotetext{
* Analiza comparată a motivelor decorative de pe statuetele diverselor civilizații va face obiectul unei alte analize, cea de față reducându-se doar la statuetele gumelniţene.
}

al lor nu poate fi decât imaginat ca fiind printrun fel de şireturi dar nici în acest caz ele nu sunt figurate.

Cercetările au relevat şi existența unor elemente de decor specifice sau mai bine zis întâlnite cu o frecvență foarte ridicată într-o anumită stațiune. Este cazul aşezării de la Căscioarele unde statuetele au un interesant decor alcătuit din cercuri incizate pe faţa şi pe spatele părții inferioare $(\mathrm{Pl} .3 / 10,11 ; 6 / 1,2)$. La mijloc aceste statuete au incizii circulare care se termină la spate prin două linii arcuite în unghi. De asemenea, majoritatea pieselor au crestătura care desparte fesele dublată de câte o incizie, foarte rar cu liniuțe oblice la interior.

Un decor special, deosebit de complex, format din combinații de elemente geometrice incizate se întâlneşte pe trunchiul şi picioarele unei statuete descoperite la Glina (Pl. 5/2).

La o parte a statuetelor se observă că decorul incizat a fost încrustat cu pastă albă sau roşie. Este posibil ca unele statuete să fi fost pictate, pe unele piese par a se mai păstra urme de vopsea roşie sau albă.

În ceea ce priveşte semnificația decorului statuetelor există două ipoteze: prima identifică motivele decorative ca fiind tatuaje, în timp ce a doua admite reprezentarea unor veşminte. $\mathrm{O}$ altă ipoteză are în vedere posibilitatea ca decorul să reprezinte o combinație de elemente reale şi elemente simbolice, adică unele motive să reprezinte într-adevăr piese sau accesorii vestimentare (chiar podoabe), iar altele să reprezinte, fie desene aflate pe aceste veşminte, fie să aibă o semnificație simbolică în sine.

Dincolo de aceste interpretări o analiză a răspândirii motivelor decorative a relevat câteva aspecte interesante.

Datele despre răspândirea statuetelor în cadrul civilizației gumelnițene sunt destul de puține şi oarecum contradictorii. Numărul lor este variabil, desigur şi în funcție de amploarea săpăturilor, dar totuşi datele de până acum par a indica o prezență foarte slabă în estul ariei gumelnițene, în special în Dobrogea.

Şi în partea de centru-est a Munteniei prezența statuetelor este relativ rară. Astfel un caz interesant este cel al stațiunii de la Sultana. Cercetările arheologice de amploare au scos la lumină unele dintre cele mai spectaculoase piese 
ale eneoliticului european şi să amintim aici numai "vasul cu îndrăgostiți”( Andreescu, Popa 2003). În schimb plastica obişnuită, din lut sau os este destul de puțin numeroasă. Chiar dacă nu avem relații despre modul de prelevare a materialului în cercetările anterioare, reluarea lor (Andreescu, Lazăr 2005) pare a confirma faptul că această plastică este puțin numeroasă. În cele cinci campanii (2001-2005) au fost descoperite numai 10 piese, la care se adaugă circa 40 , descoperite anterior (Andrieşescu 1924, Isăcescu 1984).

Un alt caz interesant este cel al lotului din aşezarea de tip tell de la Vităneşti, aflat pe valea Teleormanului, în vestul Munteniei. Deși cercetările au fost începute în anul 1993, ele nu au afectat decât o mică parte din suprafața locuirii gumelnițene (Andreescu, Mirea, Apope 2003). $\mathrm{Cu}$ toate astea numărul de statuete de lut este foarte mare, în jur de 200.

La Căscioarele unde cercetările au avut o amploare relativ mare (Dumitrescu 1965) au fost descoperite în jur de 330 statute.

Toate aceste date ridică o întrebare firească, putem vorbi despre un fenomen al statuetelor gumelnițene generalizat la nivelul întregii civilizații? Percepția aproape unanimă este aceea a unei echivalenţe între staţiune şi statuete. Iată însă că el este prezent în proporții diferite de la stațiune la stațiune şi de la o zonă la alta. Care ar fi explicatiiile acestui fenomen? Poate au existat în cadrul evoluției societății gumelnițene perioade în care aceste statuete sunt mai frecvent utilizate urmate de perioade în care, din diverse motive, ele sunt mai puțin utilizate. Poate că existau anumite zone în care fenomenul este mai intens, legat fiind de anumite caracteristici ale comunitătilor respective. În acest sens una din teoriile despre semnificația statuetelor vorbește despre afirmarea identității individuale şi de grup ale acestor comunități prin intermediul acestora (Bailey 2000).

Ar fi posibil ca cele două tipuri de decor să reprezinte un mod de identificare? Acesta se poate referi la comunități dintr-o anumită zonă care au comun un tip de decor care poate reprezenta spre exemplu un tip de veşmânt.

Detaliind analiza, aceste statuete pot reda anumite personaje din cadrul comunităţii care au o anumită poziție sau atribuție, lider sau personaj investit cu atribuții spirituale (preot, şaman), identificabile prin aceste elemente de decor.

Un lucru credem că e cert, prezența celor două tipuri de decor nu este întâmplătoare. Ele ar putea reprezenta un element de identificare despre ale cărei semnificații nu putem decât să emitem speculații în lipsa unor cercetării de amploare care să vizeze spre exemplu un grup de stațiuni. Oricum, descoperirile din vestul Munteniei par a indica faptul că aici tipul II de decor era mai utilizat, putând fi în acest fel un element de identificare al comunităților din această zonă.

Variația motivelor decorative se poate explica, cel puțin parțial, prin proveniența lor de pe diverse paliere cronologice. O diferență de 100 de ani, adică patru generații, e mai mult decât suficiență pentru schimbări, uneori chiar majore la nivelul reprezentării decorului. Acestea pot avea cauze interne (mod personal de exprimare al meşterului) sau externe (influența unei alte teme cultice apărută în altă zonă).

Numărul foarte mic de statuete descoperit în culturile anterioare culturii Gumelnița face dificilă găsirea unor modele inițiale. Anumite motive, cum sunt spiralele şi cercurile par a proveni din cultura Boian, şi ele dăinuiesc cel puțin în perioada de început a civilizației gumelniţene. Unele dintre ele par totuşi a prefigura tipurile de decor descrise mai sus. Astfel o piesă de la Tangîru din perioada de tranziție de la Boian la Gumelnița conține elemente care amintesc de tipul II de decor (Comşa 1974). Acelaşi tip de decor pare a fi mai bine conturat pe un fragment de statuetă descoperit în aşezarea de la Vidra (Rosetti 1939), aparținând fazei Gumelnița A1 (Pl. 4/6).

Lipsa unei documentării adecvate împiedică formularea unor teorii mai clare şi lasă câmp liber speculațiilor. Aceasta se datorează în primul rând lipsei cercetărilor arheologice de amploare în aşezările civilizației gumelnițene. Cercetările din ultimii, reduse ca amploare şi buget, au contribuit din păcate prea puțin la cunoaşterea ansamblului strălucitei civilizații gumelnițene. 


\section{BIBLIOGRAFIE}

Andreescu 2002 - R. Andreescu, Plastica antropomorfă gumelnițeană, Bucureşti, 2002.

Andreescu, Popa 2003 - R. Andreescu, T. Popa, Sultana Malu Roşu. Catalog selectiv, Cercetări Arheologice XII, Bucureşti, 2003, p. 59-70.

Andreescu, Lazăr 2005 - R. Andreescu, C. Lazăr, Sultana, Cronica Cercetărilor Arheologice, campania 2004, Bucureşti, 2005, p.365-367.

Andreescu, Mirea, Apope 2003 - R. Andreescu, P. Mirea, Ş. Apope, Cultura Gumelnița în vestul Munteniei. Aşezarea de la Vităneşti, jud. Teleorman, Cercetări Arheologice XII, 2003, p. 71-87.

Andrieşescu 1924 - I. Andrieşescu, Les fouiiles de Sultana, Dacia, I, 1924, 51-107.

Bailey 2000 - D. Bailey, Balkan Prehistory, Routledge, London, 2000.

Comşa 1974 - E. Comşa, Istoria comunităților culturii Boian, Bucureşti, 1974.

Dumitrescu 1965 - Vl. Dumitrescu, Principalele rezultate ale primelor două campanii de săpături din aşezarea neolitică târzie de la Căscioarel, SCIV 2, 1965, p.215-238).

Isăcescu 1984 - C. Isăcescu, Stațiunea eneolitică de la Sultana-com Mînăstirea, Documente recent descoperite şi informații arheologice, Bucureşti, 1984, p. 11-20; Săpăturile de salvare de la Sultana, com Mînăstirea, jud. Călăraşi, Ceretări Arheologice, VII, Bucureşti, 1984, p. 27-42.

Monah 1997 - D. Monah, Plastica antropomorfă a culturii Cucuteni-Tripolie, Piatra-Neamț, 1997.

Rosetti 1939 - D. Rosetti, Steinkupferzeitliche plastik aus einem wohnhugel bei Bucharest, JPEK, 12/1938, Berlin, 1939.

\section{LIST OF ILLUSTRATIONS}

Fig. 1. Decoration type IA.

Fig. 2. Decoration type IB.

Fig. 3. Decoration type II.

Pl. 1. Decoration type IA; Decoration type IB.

P1. 2. Decoration type II.

P1. 3. Decoration of Gumelniţa figurines.

Pl. 4. Decoration of Gumelniţa figurines.

Pl. 5. Decoration of Gumelniţa figurines.

Pl. 6. Decoration of Gumelnița figurines.

Pl. 7. Decoration of Gumelnița figurines.

\section{Radian-Romus Andreescu}

Muzeul Național de Istorie a României,

Calea Victoriei nr. 12, Bucureşti,

radian_romus@yahoo.com 